\title{
Performance Evaluation of Flexible Pavement for Critical Parameters Causing Premature Failure
}

\author{
Sabir S. Sayyed, Anand B. Tapase, Ravindra P. Patil, A. C. Attar, Piyush G. Chandak
}

\begin{abstract}
The present study focusses on the performance of flexible pavement at a different temperature. The analysis is carried out using $2 D$ axisymmetric finite element model for a combination of varying thicknesses of a bituminous layer with base and sub-base. The study is very much useful to know the behaviour of flexible pavement under varying climatic conditions along with loading and material properties. The critical parameters are examined to know the cause of failure of the existing pavement structure. The study evaluates different pavement distresses in terms of rutting and fatigue life.
\end{abstract}

Keywords: Rutting, Fatigue, Premature Failure, Flexible Pavement

\section{INTRODUCTION}

Recent development in automobile sector causes entry of very heavy multi-axle trucks which were not considered in design manuals in many parts of the world. Increased traffic with more number of commercial vehicles moving on existing pavement much beyond its capacity. This critical loading parameter along with varying climatic conditions like temperature makes it more complex to forecast the performance of pavement which demands development of an analytical tool to accommodate all such critical issues which is not the part of existing pavement design procedure. Deterioration of pavement starts immediately after its opening to traffic, in its early age the process is slow but shows significant effect later on, which starts with the formation of different types of cracking which is ultimately a result of fatigue or rutting failure at critical locations. Developing country like India where infrastructure facilities are the backbone of development in all aspect but due to the failure of pavement before its design life causes huge loss for maintenance and construction for these deteriorated pavement structure.

This issue investigated by changing thicknesses of various layers with varying material properties for a different combination of bituminous layers. The analysis is carried out

Revised Manuscript Received on November 08, 2019.

* Correspondence Author

Mr. Sabir S. Sayyed, Ph.D. Student, Visvesvaraya Technological University, Belagavi, India, sssabirsayyad@gmail.com

Dr. Anand B. Tapase*, ${ }^{1}$ Assistant Professor, Rayat Shikshan Santha's, Karmaveer Bhaurao Patil College of Engineering, Satara, India, tapaseanand@gmail.com

Dr. Ravindra P. Patil, Professor, Jain AGMIT, Jamkhandi, India, ravindrappatil@gmail.com

Dr. Abdulrashid C. Attar*, Professor, Rayat Shikshan Santha's, Karmaveer Bhaurao Patil College of Engineering, Satara, India, principal@kbpcoes.edu.in

Mr. Piyush G. Chandak, Ph.D. Student, Visvesvaraya Technological University, Belagavi, India, chandak.p.88@gmail.com

using $2 \mathrm{D}$ axis symmetric finite element model to identify the behaviour of flexible pavement at varying temperature conditions. This analysis can be useful to identify possible materials for different temperatures as per IRC 37 (2012) [11]. The tensile strain below bituminous layer along with compressive strain over subgrade layer are critical parameters while analysing the performance of the flexible pavement.

The procedure for a failure of pavement starts due to many factors like fatigue, rutting, temperature, and seepage with their individual and combined effect together. In India the basic occupation of people based on agriculture and allied activities where around $70 \%$ people are living in the rural part of the country and they are dependent on a nearby urban area for all other important activities and used to travel frequently as per their needs. Even though there is a number of advancement in the road sector due to increasing urbanization the basic road users are using the vehicles more than its legal load carrying capacity, even up to 2 to 2.5 times than allowable loading condition for transporting agricultural based materials. On the other hand uneven climatical /environmental conditions, unpredictable rainfall, severe hot and cold climate are leading to be major cause in the deterioration of roads in the form of rutting and fatigue.

In many parts of the world the design of flexible pavement is based considering an only empirical approach which leads to either the early failure of pavement or uneconomical pavement section, to avoid this situation the current design procedure has to be updated with experimentation result for a different set of environmental condition with different material properties. (AASHTO, Huang [9]. Piyush Chandak et al. [16] reported that the current design procedure has to be updated to give more economical section considering all such critical parameters and their influence on flexible pavement. To decide such design procedure an analytical tool has to be developed which will avoid the costly and time-consuming process of actual construction of pavement and their experimentation. In this regards application of finite element model for $2 \mathrm{D}$ axis symmetric condition seems to be a sound solution to overcome this hurdle. Rutting and fatigue are two different significant modes of distresses and has to be analyzed differently at two different positions i.e. Tensile strain (Horizontally) at bottom of a bituminous layer and compressive strain (Vertically) above the subgrade layer. Beyond its acceptable limit for fatigue and rutting lives gives rise to different types of failures in the form of various types of cracking. 
By varying thicknesses of pavement layer with different materials to calculate rutting and fatigue values of the pavement for a particular environmental condition. Such validated model seems to be very much useful to revise the design charts and procedures to surpass mechanistic-empirical design approach. Different thicknesses and material properties for the analysis were considered with reference to design manual of flexible pavement i.e. IRC 37 (2012) [11]. The correlation between findings of the work with actual field condition has to be done to achieve equilibrium between fatigue and rutting lives of pavement.

\section{REVIEW}

In Over the years number of pavement response models are developed basically which starts from Boussinesq's one-layer model to find stresses, strains, and deflection for homogenous, isotropic, linear elastic theory. The study was more useful for different layers of pavement with same stiffness values. Burmister presented multilayered pavement section which can be examined by finite element model. Huang Y Yang [9] identified various factors like frost infiltration, ground water, freezing index which has to be focused to know their influence on the performance of the pavement. Helwany Sam et al. [8] applied varying loads with different axle load configuration, varying tyre pressure for elastic and non-elastic materials and proposed necessity of finite element model to predict its effect on behaviour of flexible pavement.

Arpan Ghosha et al. [5] studied various factors like pavement temperature, the material characterization in accordance to current design procedure in India, to know their effect on pavement performance using AASHTOWARE software. The study shows that bituminous layer thickness should have more thickness when compared with constructed pavement cross section.

Tapase et al. [25] analyses critical parameters by varying materials and thicknesses of different layers to show the usefulness of finite element model. Increased bituminous layer thickness shows decreasing values of tensile strain and compressive strain. Ranadive M. S. et al. [21] reported that reduced base and sub base thicknesses show more deflection on pavement surfaces.

R. M. Mulungye et al. [17] informed that by variation in wheel configuration, tyre pressure and axle load on soft subgrade and compared with actual field data by recognizing the use of finite element modeling. Such validated model seems to be very useful to forecast the behaviour of the flexible pavement. Rahman M.T, et al. [18] studied different parameters like axle configuration, tyre imprint to find its effect by finite element analysis using ABAQUS software. The study shows that tyre imprint having two semicircles on either side of a rectangle was more accurate than other tyre imprints.

Guangming Wang et al. [7] examines by varying tyre pressure with different axle configuration using finite element and developed pavement interaction model validated with actual field data. The major finding of the study shows that single tyre (super-size) damages more near the surface than wide-based tyres. Yuhong Wang et al [26] suggested that pavement can be designed for heavily trafficked pavement as after its extensive use lacking between bonding and air voids acts separately and together. The main cause of failure of pavement has to be addressed and good maintenance practice should be followed during different phases of construction as per changing climatic condition.

Sanaa Masad et al. [24] reported that bottom side of asphalt layer shows higher tensile stresses for consideration of anisotropic material characterization for different layers of pavement, when evaluated with National Cooperative Highway Research Program (NCHRP) 1-37 [14] models. Andrew Chiasson et al. [2] studied the relation between temperature distribution and thermal stresses by 2-dimensional finite element modeling. Immanuel et al. [10] predicted stresses in base and subgrade by elastic analysis and was compared with field data which shows that this method of analysis is appropriate for dynamic loading under varying environmental and loading conditions.

Raj V. Siddharthan et al. [19] established design methodology for bulky off-road vehicles by consideration of varying climatic and environmental condition. Animesh Das et al. [3] proposed a new design methodology for Indian condition with consideration of heavy traffic where rutting and fatigue are the main criteria to decide safe pavement section.

$\mathrm{Xu}$ Yang et al. [27] predicted the performance of pavement by AASHTOWARE software. The effect of temperature variation with other climatic factors are discussed rigorously. Zuo et al. [29] reported that seasonal temperature changes, and moisture percentage in different layers of pavement disturbs pavement life assessment. Diefenderfer et al. [6] suggested a pavement model which can be used to decide a framework of temperature levels along with pavement characteristics.

Omran Maadani et al. [15] develops a model to forecast the pavement performance which based on linear elastic analysis with permanent deformation. The predicted rutting values for warmer regions were $50 \%$ more than that of colder regions. The thickness limits provided by Mechanistic Empirical Pavement Design Guide (MEPDG) was not that much affect the performance of pavement when it was replaced by two different layers of similar material while it shows limited sensitivity for unbound granular materials. Mohd Rosli Mohd Hasan et al. [13] reported that various factors like temperature, precipitation causes distresses in the form of different types of cracking. Precipitation and temperature were found to be the two major parameters which dominate the longitudinal cracking.

Armando Orobioa et al. [4] suggested the hierarchical order amongst various input for traffic, loading, an environmental condition depending upon their sensitivity.

Ripunjoy Gogoi et al. [23] established a relation between fatigue and rutting distress by analyzing pavement performance for different segments, which shows that rutting increases with fatigue distress up to $5 \%$ later rutting becomes stable and cracking increases due to fatigue. Maha A. El-Shaib et al. [12] compared different methodologies based on American Association of State Highway Officials (AASHTO) 1993 and MEPDG. The study was useful for assessment of the performance of 
pavement for low subgrade strength with increased traffic with consideration of varying climatic condition.

The available literature showcased that substantial advancement has been observed in design procedures of flexible pavement. It is also seen that considerable development has been made for the use of finite element modeling for forecasting the flexible pavement performance but still there are some missing links which has to be addressed with their proper weightage in designing process.

The design charts presented in a code of practice for design of flexible pavement i.e. IRC 37 (2012) [11] is based on CBR values of subgrade and traffic input parameters in terms of traffic loading, axle configuration etc. This design procedure is basically drawn from the findings of world known transportation departments like AASHTO and NCHRP based on their experiences as per their local environmental conditions. So there is need to upgrade the current design procedure as per the temperature and seasonal changes along with different parameters like nearness of water table seepage with their combined effect on the performance of the pavement.

\section{METHODOLOGY}

The methodology framed for the current work is based on the consideration of critical parameters identified from rigorous literature survey along with in respect of different procedures described for design of flexible pavement by various institution like Indian Roads Congress (IRC), National Cooperative Highway Research Program and AASHTO standards. The performance of flexible pavement depends upon various factors like material strength, environmental conditions, type of loading, axle configuration along with tyre pressure and many more. It is obvious to calculate fatigue and rutting for forecasting the pavement life. Various types of materials and their combinations has to be used for extending pavement life. So the present study concentrate on to find an economical blend for practical field conditions to have optimum thicknesses of pavement sections for different materials and loading conditions.

For this study depending on necessity of the problem the analysis is carried out by considering temperature, freezing and thawing as a one of major phase for variation in temperature.

For this analysis a section consist of two layer of total pavement thickness $560 \mathrm{~mm}$ including $110 \mathrm{~mm}$ of bituminous layer and $450 \mathrm{~mm}$ base layer resting over subgrade soil of 900 $\mathrm{mm}$ is considered. A mesh consist of 958 nodes and 880 quadrilateral elements are considered for idealization. The horizontal extent for the analysis is about $14760 \mathrm{~mm}$ which is around 3 times of pavement width, denoting undefined horizontal extent of soil strata. A four noded quadrilateral elements are considered for the idealization by two dimensional finite element analysis.

It is observed that the boundary condition described by values of initial temperature condition at bottom of subgrade and atmospheric temperature condition. In present analysis the temperature at bottom of subgrade layer is kept constant at $22^{\circ} \mathrm{C}$ and atmospheric temperature at surface is kept constant to $42^{\circ} \mathrm{C}$. Also to calculate the temperature at any point within pavement section due to freezing negative temperature at bottom of subgrade is considered for the analysis. It can be possible to predict the temperature at any point in multilayer pavement section by doing such type of analysis if initial conditions are defined.

Investigation of Critical Parameters Initiating for Premature Failure of flexible pavements in India-

In India, various types of roads like Expressway, National Highway, State Highway, District Roads are designed as flexible pavement by referring Indian Road Congress design manual (IRC 37 - 2012) .Early deterioration of such pavements much earlier than their design life are because of various causes like varying average annual temperature, rainfall intensities, drainage condition, varying ground water depth and their negligence while design of roads.

The climatic condition in India, divides the country into six climatic zones with too much of variation in different parameters such as average annual temperature and rainfall intensities for various parts of country. Also the variation in soil types and their characteristics like CBR values which is one of the most important input parameter to decide pavement thicknesses of different layers of flexible pavement makes it more critical. It is found that design manual referred for design of flexible pavement (IRC 37-2012) is not addressing these critical parameters in detail which causes early deterioration of flexible pavement much earlier than its design life.

\section{Pavement Composition:}

The analysis was carried out by varying the thicknesses of bituminous layer ranging from 125 to $200 \mathrm{~mm}$ with top most Bituminous Concrete (BC) layer keeping constant for $100 \mathrm{~mm}$ for all the trails while the variation in Dense Bituminous Macadam (DBM) layers with $25 \mathrm{~mm}$ sub layer thickness. Granular layer thickness varied between 450 to $600 \mathrm{~mm}$. with $75 \mathrm{~mm}$. sub layer thickness while subgrade layer kept constant for $900 \mathrm{~mm}$. for all the trails. As the temperature in India varies between $50^{\circ} \mathrm{C}$ in summer in the month of April/May while drastically drops even up to $5{ }^{0} \mathrm{C}$ to $10{ }^{0} \mathrm{C}$ during winter in the month of December/January. Considering these cycles of variation for a temperature changes annual average temperature of $35{ }^{0} \mathrm{C}$ is considered for the given analysis. The different material properties along with modulus of rigidity for different layers with respect to its material types are selected as per design code of practice for flexible pavement IRC 37 (2012).

\section{Finite Element Modelling:}

Idealisation, formation, and solution of governing equation for the considered system is done by finite element model for evaluating the design procedures as reported by Tapase and Randive et al. [22]. The current pavement design procedure in India is basically considering important parameters like modulus of elasticity (E) and poison's ratio $(\mu)$. There is vast scope available for different type of material which can be encountered for construction of pavement with useful field data with different material properties along with their $(\mathrm{E})$ and $(\mu)$ values from the available literature. The considered values of $E$ and $\mu$ for the present work are shown in the fig. 1 


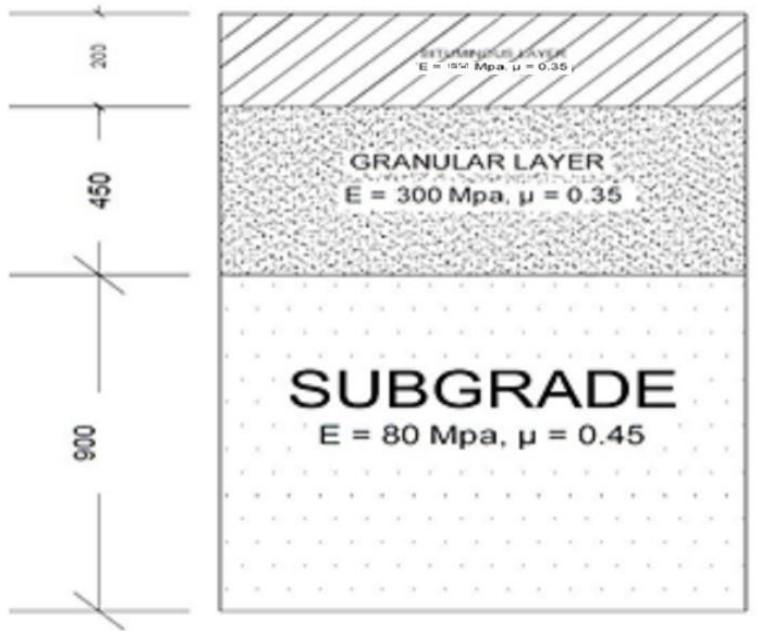

Fig. 1 Pavement Composition

\section{Finite Element Idealization:}

For variation in thicknesses with different types of materials were analyzed by a two dimensional (2D) FE model for the axisymmetric linear approach. On roadways, vehicles tend to ride at the central part of the carriageway hence retaining the axle load in a position above the central line of the roads symmetrically. A quarter model is proposed by considering the symmetry in both longitudinal and transverse direction.

Deformation analysis by both axis symmetric deformation analysis and plain strain deformation shows close values in many respect. Intensification for radiating distance from an axis of symmetry shows the difference in deformation by both methods tends to decrement. In fig. 2, idealization of a finite element model is shown where $r$ and $\mathrm{z}$ represent radial axis and an axis of symmetry respectively. Displacement component $\mathrm{u}$ and $\mathrm{v}$ are acting in radial axis ( $\mathrm{r}$ ) and axis-symmetry $(\mathrm{z})$ direction respectively. Normal strains $\varepsilon_{\mathrm{r}}, \varepsilon_{\mathrm{z}}$ and $\varepsilon_{\theta}$ in $r, z$ and circumferential directions and the shear strain $\gamma_{\mathrm{rz}}$ in the $(\mathrm{r}, \mathrm{z})$ plane are observed by axis symmetrical analysis.

The expressions are given as:

$$
\varepsilon_{\mathrm{r}}=\frac{\partial u}{\partial r}, \varepsilon_{\mathrm{z}}=\frac{\partial v}{\partial z}, \varepsilon_{\theta}=\frac{u}{r}, \gamma_{\mathrm{rz}}=\frac{\partial u}{\partial z}+\frac{\partial v}{\partial r} \quad \ldots \text { (1) }
$$

The strain vector $(\varepsilon)$ has components as defined in equation 2

$$
[\varepsilon]=\begin{array}{c|}
\hline \varepsilon_{\mathrm{r}} \\
\hline \varepsilon_{\mathrm{z}} \\
\hline \varepsilon_{\theta} \\
\hline \gamma_{\mathrm{rz}} \\
\hline
\end{array}
$$

Likewise, the stated system would undergo the normal stresses like $\sigma_{\mathrm{r}}, \sigma_{\mathrm{z}}$ and $\sigma_{\theta}$ along with shear stress $\tau_{\mathrm{rz}}$. The strain vector and the stress vector result in an equation:

$$
[\sigma]=[\mathrm{c}][\varepsilon] \ldots(3)
$$

Wherein, $\mathrm{c}$ is the deformation coefficient matrix wherein the normal strain $\varepsilon_{\mathrm{z}}$, shear stress and shear strain are considered nearly equal to zero. Finite element analysis calculates the integral energy of elements within the domain which includes the use of numerical definite integration which is evaluated by use of explicit integration and numerical integration techniques. In the present work values of complex expressions engaged by numerical integration technique with effective use of program coded in FORTRAN language. In present analysis based on Gauss Quadrature method of numerical integration by assuming quadrilateral element comprising four gauss points to get particular results.

The analysis for flexible pavement by theory of elasticity depends upon input parameters like details of loading, thickness (h), modulus of elasticity (E) and poisons ratio $(\mu)$. Boussinesq's and Burmister's closed-form solutions are used for preliminary analysis considering homogeneous, isotropic, and elastic material properties. The tyre pavement interaction is considered as axisymmetric for the present work, with a radius of $150 \mathrm{~mm}$ with circular contact area for varying thicknesses of pavement. (Ranadive et al. [20]). The standard load $80 \mathrm{KN}$ (8.16 tonnes) was applied axially with a uniform pressure of $0.575 \mathrm{MPa}$ (Tapase and Randive [26]). The extreme right boundary is fixed at 7 times the radius of the wheel. Four noded quadrilateral elements were considered for the finite element idealization.

\section{Boundary Conditions:}

The nodes lying on vertical faces i.e. along a centerline of loading and the farthest side i.e. $1050 \mathrm{~mm}$ from loading axis are restrained along radial direction while free to move along axial direction, while the nodes lying at subgrade bottom are restrained along both direction (axial and radial).

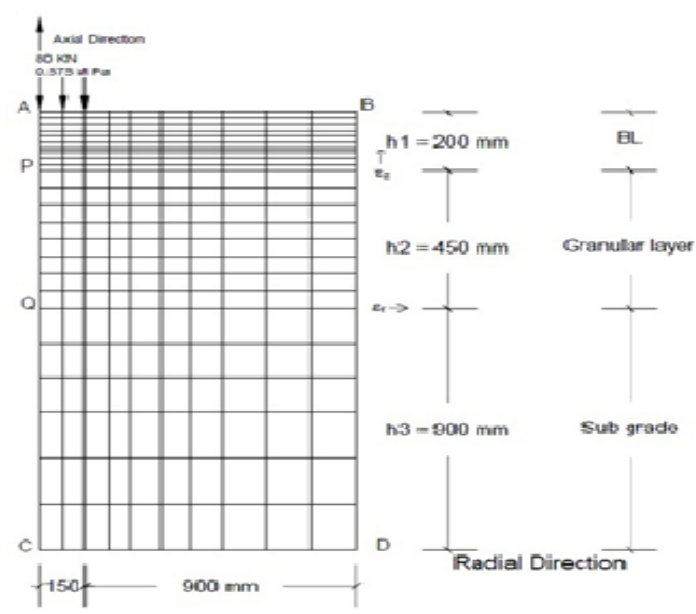

Fig. 2 Idealization of the Pavement Section.

\section{TESTS, RESULTS \& DISCUSSION}

To study the pavement performance, modulus of specific layer is kept constant for designed depth. Different codes like (IRC: 37-2012, AASHTO) suggests the modulus values for different temperature in the range of $22^{\circ} \mathrm{C}$ to $42^{\circ} \mathrm{C}$.As per design chart recommended in following chart. Bituminous concrete $50 \mathrm{~mm}, 125 \mathrm{~mm}$ of dense bituminous macadam, 250 $\mathrm{mm}$ of granular base and $200 \mathrm{~mm}$ of granular subbase while top $50 \mathrm{~mm}$ to be used remains same (i.e. value of bituminous concrete suggested by IRC 37-2012). Similarly the value of modulus of remaining layers remains same for their suggested depths. So the design engineer will proposed the thicknesses of different layers of pavement considering that the temperature will remain constant at all depths of pavement which is not correct. But on actual field conditions the temperature at top of pavement, in between layers and bottom layers for varying depths along with respective horizontal locations does not remains constant.

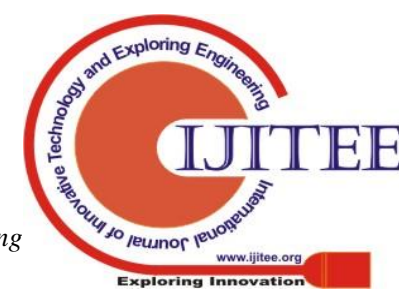


So the proper bitumen grade can be selected by accurately predicting this varying temperature for varying depths together with respective horizontal locations. So the optimum pavement section can only be proposed by considering particular environmental conditions with their effect in variation in intensity of temperature at different levels. The material for various layers can be selected by taking average temperature for that particular depth. Pavement proposed by following this philosophy not only be more stable but economic also, as it is possible to construct pavement section with suitable material for suitable depth.

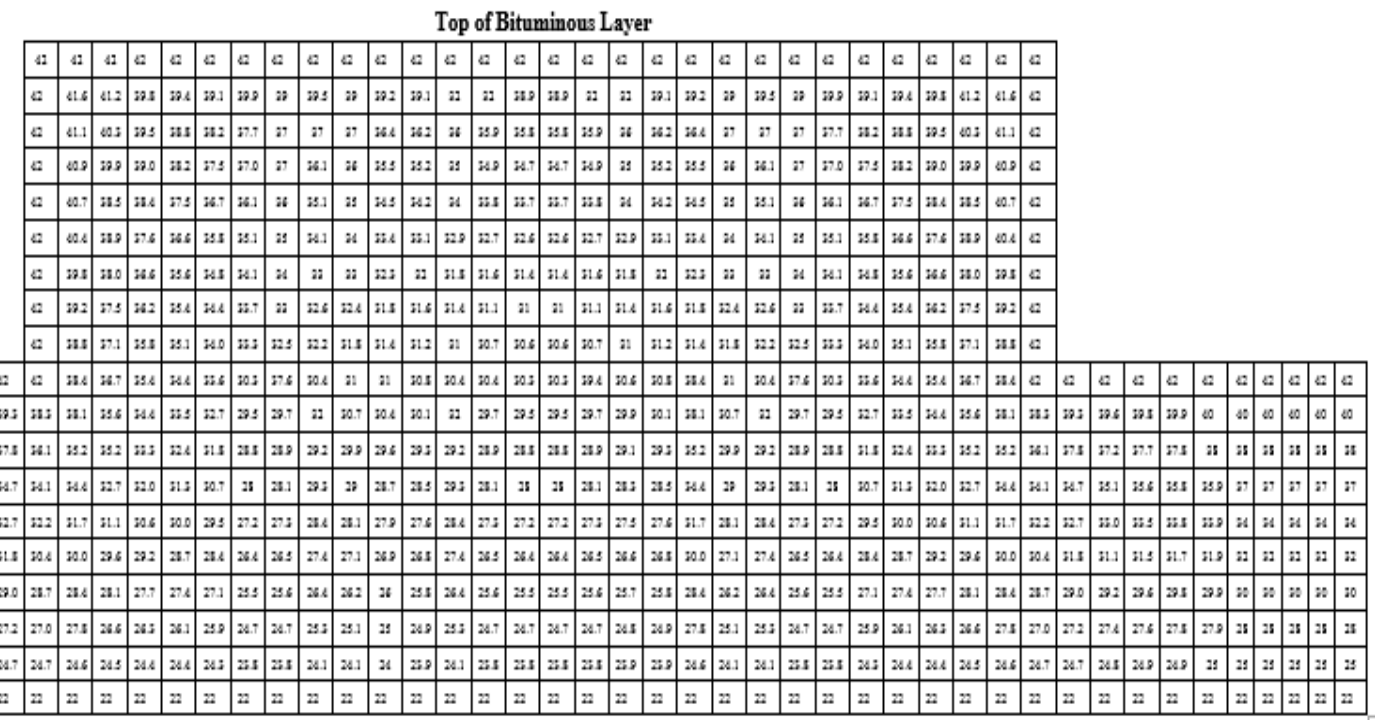

\section{Interpretation of results for variation of base thickness and material on critical parameters-}

To know the influence of variation of base thickness and base layer material property, a set of selected nine cases are considered for evaluation. Three base layer thicknesses as $300 \mathrm{~mm}, 450 \mathrm{~mm}$ and $600 \mathrm{~mm}$ are compared to observe the effect of thickness variation. Base layers are checked against three material properties for their suitability. In order to interpret the results, bituminous thickness is kept constant at $175 \mathrm{~mm}$ and material property $(\mathrm{E}=1650 \mathrm{MPa}, \mu=0.35)$ constant along with subgrade material property as $80 \mathrm{MPa}$. Obtained outcomes are equated with the allowable values of critical parameters as provided in IRC: 37-2012.

From the analysis following observations are derived,

a) The value of $\mathcal{E} \mathrm{t}$ at bottom of $\mathrm{BL}$ for natural gravel $(\mathrm{E} 1=100 \mathrm{MPa}, \mu=0.35)$ and natural gravel $(\mathrm{E} 2=300 \mathrm{MPa}$, $\mu=0.35$ ) are exceeding permissible limit at all thickness trials as shown in Figure 3.

b) It is observed that high quality graded crushed rock (E3 $=450 \mathrm{MPa}, \mu=0.35)$ the values of $\mathcal{E} \mathrm{t}$ is within the permissible limit for all base thicknesses.

c) From Figure 4, it is observed that the values of cases considered for interpretation are under the allowable limit, for $\mathcal{E}_{\mathrm{V}}$ on subgrade.

d) When base course material differs from $E 1=100 \mathrm{MPa}$, $\mu=0.35$ to $E 2=300 \mathrm{MPa}, \mu=0.35$ more than 25 percent decrease in vertical displacement is observed, wherein from $\mathrm{E} 2=300 \mathrm{MPa}$ to $\mathrm{E} 3=450 \mathrm{MPa}$ not even 2 percent decrease in vertical displacement is noticed (Figure 5). Here it is noticed that using stiffer material beyond $300 \mathrm{MPa}$ does not reduce vertical displacement, so modulus of the base layer can be restricted at $300 \mathrm{MPa}$.

e) Similarly, it is noticed that increasing thickness of base layer for next trial thickness (i.e. 600mm) gives four times less reduction in vertical displacement value.

f) For all base thickness trails, it is seen that high quality graded crushed rock $(E 3=450 \mathrm{MPa}, \mu=0.35)$ shows the values of $\mathcal{E}$ t within the acceptable limit as per IRC: $37-2012$. So, it is concluded that the high quality graded crushed rock $(\mathrm{E} 3=450 \mathrm{MPa}, \mu=0.35)$ is the best material for the selected combination (Figure 3 ).

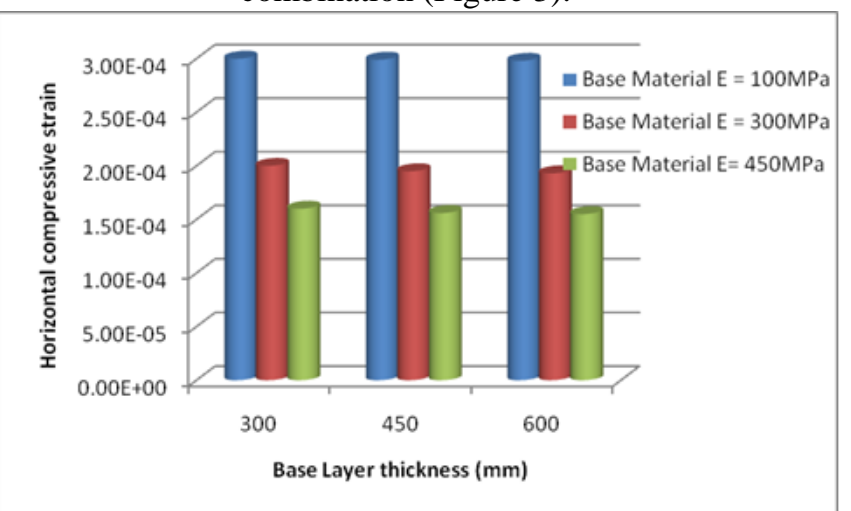

Fig.3 Base layer thickness Vs Horizontal tensile strain

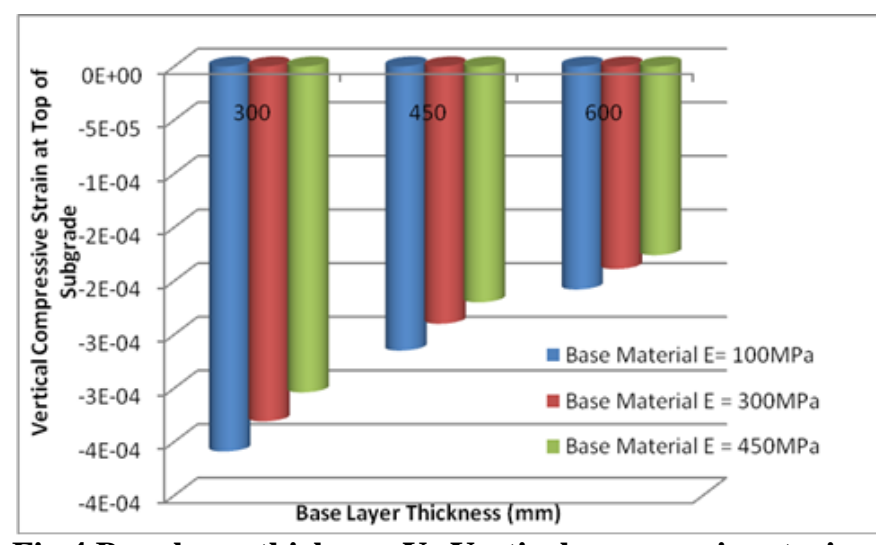

Fig.4 Base layer thickness Vs Vertical compressive strain 


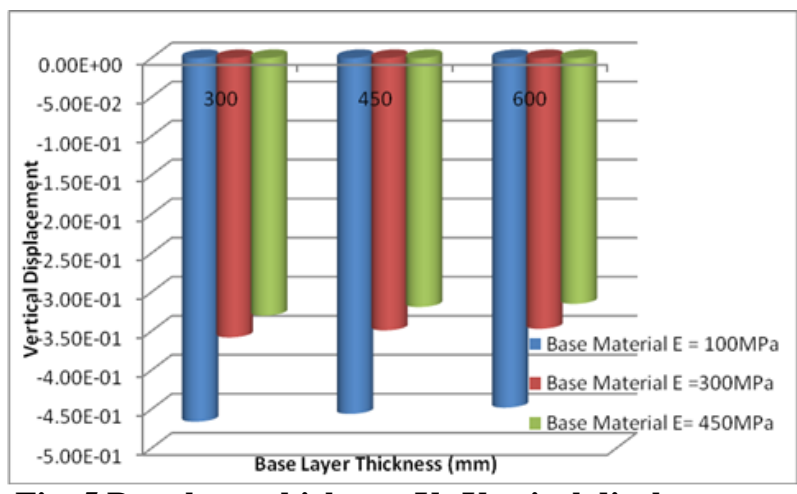

Fig. 5 Base layer thickness Vs Vertical displacement

Thickness variation of bituminous layer and variation in base layer material properties -

To know the result of variation in thickness of BL and base layer material property, four thicknesses of BL as $125 \mathrm{~mm}$, $150 \mathrm{~mm}, 175 \mathrm{~mm}$, and $200 \mathrm{~mm}$ are compared. Bituminous layers (BL) are checked against three base material properties those are natural gravels $(E=100 \mathrm{MPa}, \mu=0.35)$, natural gravel $(\mathrm{E}=300 \mathrm{MPa}, \mu=0.35)$ and high quality graded crushed rock $(E=450 \mathrm{MPa}, \mu=0.35)$ for their suitability. In order to interpret the results, thickness of base layer as $450 \mathrm{~mm}$ and material property of $\mathrm{BL}(\mathrm{E}=1650 \mathrm{MPa}, \mu=0.35)$ are kept constant along with subgrade material property as $80 \mathrm{MPa}$, likewise results reported and compared with allowable values of critical parameters as provided in IRC: 37-2012.

From the analysis following observations are derived,

a) Selected subgrade condition for a constant base thickness $(450 \mathrm{~mm})$, the values of $\mathcal{E}$ t for natural gravel $(\mathrm{E} 1=100 \mathrm{MPa}, \mu=0.35)$ exceeds permissible limits at all thickness trials (Figure 6).

b) From Figure 6, it is seen that the horizontal tensile strain at bottom of BL for natural gravel is safe at $200 \mathrm{~mm}$ thickness of BL and for high quality graded crushed rocks is safe at $175 \mathrm{~mm}$ and $200 \mathrm{~mm}$ thickness of BL.

c) From Figure 6 shows that $125 \mathrm{~mm}$ and $150 \mathrm{~mm}$ of BL thickness are not safe as far as fatigue cracking due to excess $\mathcal{E} \mathrm{t}$ is concerned for the selected combination.

d) A significant reduction in the value of $\mathcal{E}$ t is observed for every change in base layer material property, it is more than $25 \%$ for change from $100 \mathrm{MPa}$ to $300 \mathrm{Mpa}$ and $2 \%$ reduction in the value of $\mathcal{E}$ t for high quality graded crushed rock than $300 \mathrm{MPa}$.

e) From Figure 7, shows that vertical compressive strain at top of bituminous layer is within permissible limit for all cases excluding, base $\mathrm{E} 1=100 \mathrm{MPa}$ and $125 \mathrm{~mm}$ layer thickness for bituminous layer.

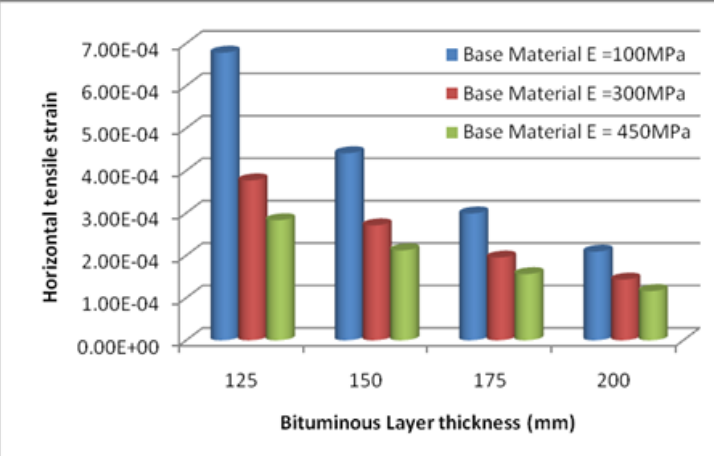

Fig.6 BL thickness Vs Horizontal tensile strain

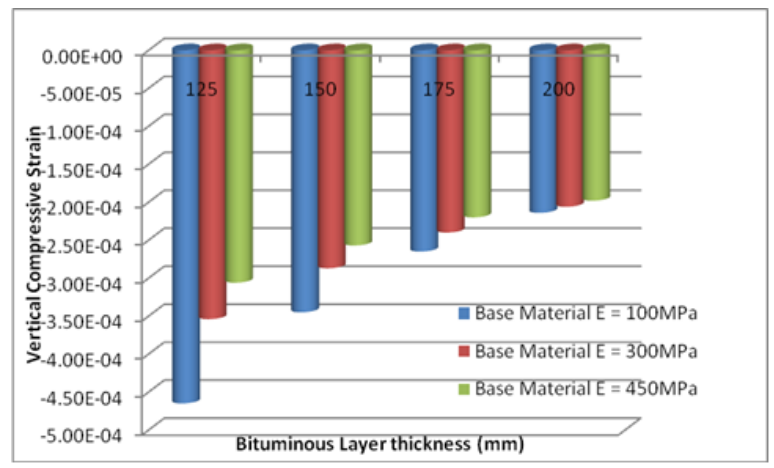

Fig.7 Bituminous layer thickness Vs Vertical compressive strain

\section{CONCLUSION}

The results reported by given analysis indicates that the average annual temperature change for upper $0 \mathrm{~mm}$ to 110 $\mathrm{mm}$ depth is $2.2^{0} \mathrm{C}$. So bituminous mix to be selected should consider this reported average annual temperature, together with the testing to be carried out to find modulus of bituminous mix for average annual temperature of $38.5^{\circ} \mathrm{C}$.

Also to relate the procedure with practical conditions local appropriate temperature, freezing and thawing records can be produced as boundary conditions for top of surface and bottom of subgrade levels. The variations in temperature can be predicted by this analysis can be used to select the appropriate materials for different layers of pavement depending on its material characteristics. Even hypothetically designed pavement section can be rearranged to get more stable, economic and ultimately optimum design for particular specific climatic and soil conditions.

The pavement responses including stresses, strains, and deflection which are evaluated from the structural models are used as inputs for distress models. The distress models include fatigue and rutting criteria. In the present investigation, the calibrated fatigue model and a rutting model is used to estimate the fatigue life in terms of a number of the standard axles and the rutting life in terms of a number of cumulative standard axles respectively, both models for $80 \%$ reliability level given in IRC: 37-2012 are employed. The computed strains are taken as input and are incorporated in the fatigue and rutting criteria recommended in Indian Road Congress (IRC: 37-2012) to estimate the pavement life for various hypothetical conditions.

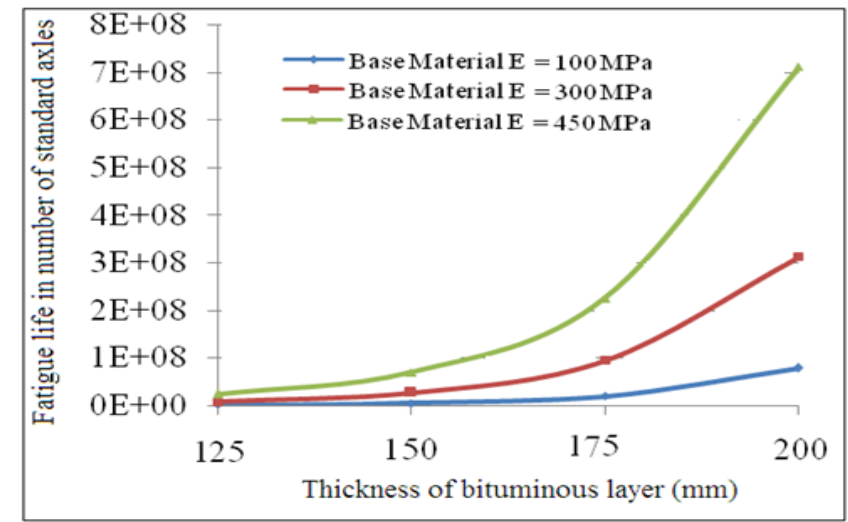

Fig.8 Fatigue life in number of standard axles Vs Thickness of BL. 


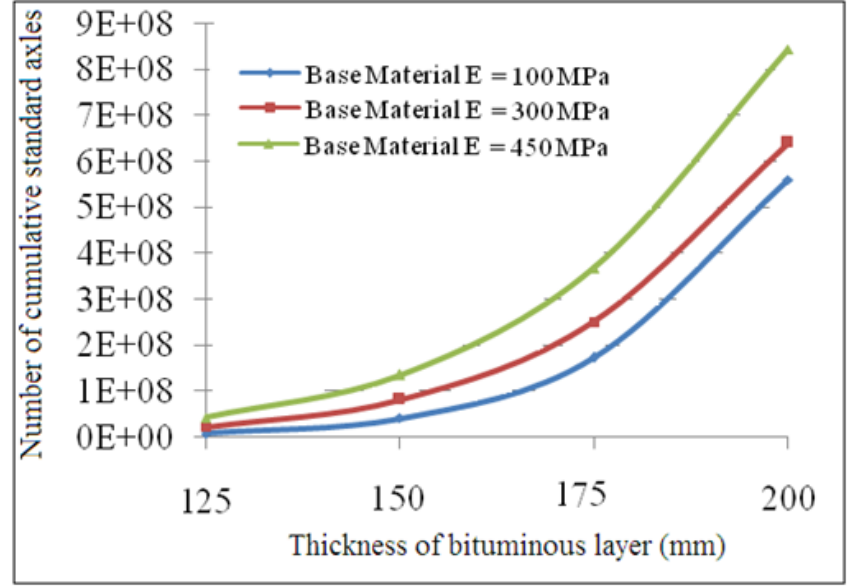

Fig. 9 Number of cumulative standard axles Vs Thickness of BL.

The fatigue cracking of flexible pavements is based on the horizontal tensile strain at the bottom of BL. On this criterion, the allowable number of load repetitions, $\left(N_{f}\right)$ that causes fatigue cracking is related to the tensile strain $\left(\mathcal{E}_{t}\right)$ at the bottom of BL. Figure 8 gives a graphical presentation of fatigue life in a number of standard axles on the $y$-axis versus the thickness of the $\mathrm{BL}$ on the $\mathrm{x}$-axis for all trail base material. Figure 9 gives a graphical presentation of a number of cumulative standard axles on the $y$-axis versus the thickness of the $\mathrm{BL}$ on the $\mathrm{x}$-axis for all trail base material.

\section{REFERENCES}

1. American Association of State Highway Officials AASHTO (1993). AASHTO guide for the design of pavement structures. AASHTO, Washington, D.C.

2. Andrew Chiasson, Cenk Yavuzturk, Khaled Ksaibati (2008). "Linearized approach for predicting thermal stresses in asphalt pavements due to environmental conditions." Journal of Materials in Civil Engineering. ASCE, 20(2), 118-127. doi: 10.1061/ (ASCE)0899-1561(2008)20:2 (118).

3. Animesh, Das, Pandey, B.B. (1999). "The m-e design of bituminous road: An Indian perspective.” Journal of Transportation Engineering, ASCE, 125(5), 463-471. doi: 10.1061/ (ASCE) 0733-947X (1999)125:5(463).

4. Armando Orobioa and John P. Zaniewskib (2013). "Sensitivity of the mechanistic-empirical pavement design guide to traffic inputs: a space-filling approach." Road Materials and pavement design, Taylor \& Francis, 14(3), 735-746, doi: 10.1080/14680629.2013.816248.

5. Arpan Ghosha A. Padmarekhab J. Murali Krishnanc (2013) "Implementation and Proof-Checking of Mechanistic-Empirical Pavement Design for Indian Highways Using AASHTOWARE Pavement ME Design Software." Procedia-Social and Behavioral Sciences 119-128 doi: 10.1016/j.sbspro.2013.11.104

6. Diefenderfer, B. K., Al-Qadi, I. L., and Diefenderfer, S. D. (2006). Model to predict pavement temperature profile: development and validation. Journal of Transportation Engineering, ASCE, 132(2), 162-167.

7. Guangming Wang and Reynaldo Roque (2011). "Evaluation of truck tyre types on near-surface pavement response based on finite element analysis." International Journal of Pavement Research and Technology, 4(4), 203-211.

8. Helwany, Sam, Dyer, John, Joeleidy (1998). "Finite element analysis of flexible pavement." Journal of Transportation Engineering, ASCE, 124(5), 491-499. doi: 10.1061/(ASCE)0733 947X(1998)124:5(491).

9. Huang H.Yang (2008). Pavement analysis and design, Pearson Education Inc, and Dorling Kindersley Publishing, Inc, second edition.

10. Immanuel, S., and Timm, D. H. (2006). Measured and Theoretical Pressures in Base and Subgrade Layers under Dynamic Truck Loading. Proceeding, 2006 Airfield and Highway Pavement Specialty Conference, American Society of Civil Engineers, 155-166.

11. IRC: 37-2012. Guidelines for the design of flexible pavements. Indian Roads Congress, New Delhi.

12. Maha A. El-shaib, Sherif M. El-Badawy, El-Sayed A. Shawaly (2017). "Comparison of AASHTO 1993 and MEPDG considering the Egyptian climatic conditions." Innovative Infrastructure Solution.
Springer International Publishing Switzerland. doi: 2(18), doi:10.1007/s41062-017-0067-6.

13. Mohd Rosli Mohd Hasan, Jacob E. Hiller and Zhanping You (2015) "Effects of mean annual temperature and mean annual precipitation on the performance of flexible pavement using ME design." International Journal of Pavement Engineering, doi.org/10.1080/10298436.2015.1019504.

14. NCHRP (2007). Evaluation of mechanistic-empirical design procedure. National Cooperative Highway Research Program, NCHRP Project 1-37A, National Research Council, Washington.

15. Omran Maadani and A. O. Abd El Halim, (2017) "Environmental Considerations in the AASHTO Mechanistic-Empirical Pavement Design Guide: Impacts on Performance." Journal of Cold Regions Engineering, ASCE, ISSN 0887-381X

16. Piyush G. Chandak, Anand B. Tapase, Sabir S. Sayyed, Abdulrashid C. Attar (2017). "A State-of-the-Art Review of Different Conditions Influencing the Behavioral Aspects of Flexible Pavement." Advancement in the Design and Performance of Sustainable Asphalt Pavements, Springer International Publishing, 300-312, doi 10.1007/978-3-319-61908-8_22.

17. R.M. Mulungye, P.M.O. Owende and K. Mellon (2007). "Finite element modeling of flexible pavement on soft soil subgrades." Materials and Design. Elsevier. (28), 739-756.

18. Rahman M.T, Mahmud K and Ahsan S (2011). Stress-Strain characteristics of flexible pavement using finite element analysis. International Journal of Civil and Structural Engineering, 2(1), $233-240$

19. Raj V. Siddharthan, Peter E. Sebaaly, Magdy El-Desouky, Dan Strand and David Huft (2005). "Heavy off-road vehicle tyre-pavement interaction and response." Journal of Transportation Engineering, ASCE, 131(3), 239-247. Doi: 10.1061/ (ASCE) 0733-947X (2005) 131:3(239).

20. Ranadive, M.S and Anand B. Tapase (2016). "Parameter sensitive analysis of flexible pavement." International Journal of Pavement Research and Technology (IJPRT), Elsevier, Special Issue on Sustainability on Pavement Engineering. doi:10.1016/j.ijprt.2016.12.001.

21. Ranadive, M.S. \& Tapase, A. (2016). "Pavement performance evaluation for different combinations of temperature conditions and bituminous mixes." Innovative Infrastructure Solutions, Springer 1 (40), doi: 0.1007/s41062-016-0040-9.

22. Ranadive, M.S., Tapase, A.B. (2013). "Investigation of behavioral aspects of flexible pavement under various conditions by finite element method." Constitutive modeling of geomaterials, doi: 10.1007/978-3-642-32814-5_100

23. Ripunjoy Gogoi, Animesh Das and Partha Chakraborty (2013). "Are fatigue and rutting distress modes related?." International Journal of Pavement Research and Technology, 6(4), 269-273

24. Sanaa Masad, Dallas Little and Eyad Masad (2006). "Analysis of flexible pavement response and performance using isotropic and anisotropic material properties." Journal of Transportation Engineering, ASCE, 132(4), 342-349.

25. Tapase A.B., Ranadive M.S. (2017) "Predicting Performance of Flexible Pavement Using Finite Element Method." Advancement in the Design and Performance of Sustainable Asphalt Pavements. Sustainable Civil Infrastructures. doi.org/10.1007/978-3-319-61908-8_11.

26. Tapase A, Ranadive M (2016). "Performance evaluation of flexible pavement using finite element method." Material, Design, Construction, Maintenance and testing of pavement, doi: 10.1061/9780784480090.002.

27. Xu Yang, Zhanping You, Jacob Hiller and David Watkins (2015) "Sensitivity of flexible pavement design to Michigan's climatic inputs using pavement ME design." International Journal of Pavement Engineering, Taylor \& $\quad$ Francis doi.org/10.1080/10298436.2015.1105373

28. Yuhong Wang and Dan Chong (2015) "Long-Life Flexible Pavement: Myth, Reality, and the Way Forward." ASCE New Frontiers in Road and Airport Engineering, 268-283.

29. Zuo, G., Drumm, E. C., and Meier, R. W. (2007). "Environmental effects on the predicted service life of flexible pavements." J. Transp. Eng., 133(1), 47-56. 


\section{AUTHORS PROFILE}

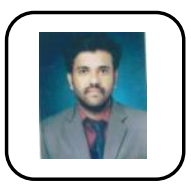

Mr. Sabir S. Sayyed, M.E. Civil (Construction Management) is currently pursuing Ph.D. in Transportation engineering specializing in Performance Analysis of Flexible Pavement. He has previously published research papers titled "Evaluation and Remedial Measures on Premature Failure of Roads in India "published in 'Journal of Performance of Constructed Facilities', American Society for Civil Engineers (ASCE); "Performance Evaluation of Low Volume Rural Roads - A State of the Art Review" published in "New Developments in Soil Characterization and Soil Stability', Sustainable Civil Infrastructures, Springer International Publishing AG. "Review and Assessment of Flexible Pavement" published in 'Advancements on Civil Infrastructures', Sustainable Civil Infrastructures, Springer International Publishing AG; "A State-of-the-Art Review of Different Conditions Influencing the Behavioral Aspects of Flexible Pavement" published in 'Advancement in the Design and Performance of Sustainable Asphalt Pavements', Springer International Publishing. He is the reviewer for three journals titled 'Journal of Performance of Constructed Facilities', ASCE; 'Environment, Development and Sustainability', Springer International publishing and 'Soft Computing in Civil Engineering', Pouyan press publications

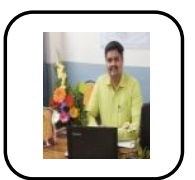

Dr. Anand B.Tapase is currently working as professor KBP College of engineering, Satara and has an overall experience of 12 years. His area of expertise is in Transportation engineering and Construction Management. He is guiding 2 Ph.D. students and has published $12 \mathrm{SCI} / \mathrm{SSCI}$ Indexed Articles, 4 SCOPUS Indexed Articles and has 64 google scholar citations to his name. He has been selected as technical committee member for GEO-China 2021. He is also a member of American Society for Civil Engineers (ASCE). His latest paper titled "Evaluation and Remedial Measures on Premature Failure of Roads in India" has been accepted for publication in 'Journal of Performance of Constructed Facilities', American Society for Civil Engineers (ASCE)

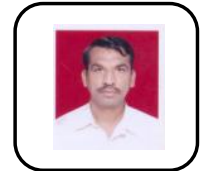

Dr. Ravindra P. Patil, is currently working as Executive Director at AGM Institute of Technology, Jamkhandi. He is guiding four Ph.D. students. He has published 7 peer reviewed research papers in reputed journals. His area of specialization is Structural engineering and has an overall teaching experience of 26 years. He is currently mentoring $4 \mathrm{Ph} . \mathrm{D}$. students and working in the field of transportation engineering. He is also a member of various local professional bodies

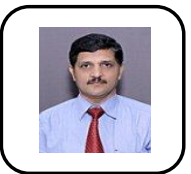

Dr. Abdulrashid C. Attar is currently working as Principal, KBP College of engineering, Satara and has an overall experience of 25 years. His area of expertise is in Value engineering and Construction Management. He is guiding $4 \mathrm{Ph} . \mathrm{D}$. students and has published $46 \mathrm{SCI} / \mathrm{SSCI}$ Indexed Articles, 2 SCOPUS Indexed Articles and has 34 google scholar citations to his name. His latest paper titled "Evaluation and Remedial Measures on Premature Failure of Roads in India" has been accepted for publication in 'Journal of Performance of Constructed Facilities', American Society for Civil Engineers (ASCE). He has been awarded 'Distinguished Faculty in Engineering' by Venus International Faculty awards.

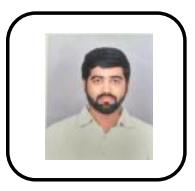

Mr. Piyush G. Chandak, M.E. Civil (Construction Management) is currently pursuing Ph.D. in Transportation engineering specializing in low volume rural roads. He has previously published research papers titled "Evaluation and Remedial Measures on Premature Failure of Roads in India "published in 'Journal of Performance of Constructed Facilities', American Society for Civil Engineers (ASCE); "Performance Evaluation of Low Volume Rural Roads A State of the Art Review" published in "New Developments in Soil Characterization and Soil Stability', Sustainable Civil Infrastructures, Springer International Publishing AG. . He is the reviewer for three journals titled 'Journal of Performance of Constructed Facilities', ASCE; 'Environment, Development and Sustainability', Springer International publishing and 'Soft Computing in Civil Engineering', Pouyan press publications. 